\title{
Shear and Flexural Strengthening of Reinforced Concrete Beams with Titanium Alloy Bars
}

\author{
Christopher Higgins', Jonathan Knudtsen', Deanna Amneus², Laura Barker³ \\ ${ }^{1}$ Oregon State University \\ Corvallis, OR, USA \\ chris.higgins@oregonstate.edu; knudtsej@oregonstate.edu \\ ${ }^{2}$ Mackenzie \\ Portland, OR, USA \\ amneusd@onid.oregonstate.edu \\ ${ }^{3}$ David Evans and Associates \\ Salem, OR, USA \\ barkerl@oregonstate.edu
}

\begin{abstract}
Many older reinforced concrete (RC) structures are identified as deficient in flexure and/or shear when applying modern design standards for their evaluation. The deficiencies most often are due to inadequate amounts of reinforcing steel and/or poor reinforcing details. To prevent the need for expensive replacements it is desirable to extend their service life by strengthening them. Strengthening approaches must be both structurally efficient and cost-effective. Titanium alloy bars (TiABs) offer a new opportunity to strengthen such existing structures that has not previously been investigated, due primarily to the perception of high cost. However, titanium's combination of strength, ductility, durability, and ability to form mechanical anchorages are essential characteristics for effective repair and retrofit applications and are advantageous over competing materials such as steel and fiber-reinforced polymer (FRP) products. Round TiABs with unique deformation patterns were specially developed for strengthening RC griders. Research using the TiABs to strengthen RC bridge girders in both flexure and shear was undertaken in the laboratory through full-scale tests. Realistic girder specimens were constructed, instrumented, and tested to failure. The specimens mimicked the in situ materials, loading interactions, and geometry of typical mid-20th century reinforced concrete deck girder bridges that were widely used in the US. The details and proportions of these structures are similar to others around the world. Using the findings, the flexural strengthening techniques were applied to a bridge overcrossing of a major interstate highway in the US. This first ever application of titanium alloy bars to a reinforced concrete bridge was completed at a $30 \%$ cost savings compared to alternative designs.
\end{abstract}

Keywords: Titanium alloy, NSM, strengthening, rehabilitation, reinforced concrete, flexure, shear

\section{Introduction}

Large numbers of conventionally reinforced concrete structures remain in service around the world that are considered deficient for modern loading requirements or hazards. Many were constructed in the post-war era at the time reinforcing bars were being standardized. Early standardization of the deformation requirements dramatically changed bond provisions in relevant design codes. This resulted in poorly detailed members and inadequate transverse steel (called stirrups in North American practice). Application of modern design provisions to assess vintage RC members typically results in low reserve capacity. Load restrictions or replacements are expensive and thus structurally effective and economical strengthening approaches are required.

A typical strengthening approach uses fiber reinforced polymer (FRP) materials. FRP is elastic until fracture and provides no ductility. FRPs can also debond prematurely limiting effectiveness. Here we propose a new material for use in a near-surface mounting (NSM) application to provide supplemental reinforcing. In this method, titanium alloy bars (TiABs) are bonded with structural adhesive within grooves that are cut into the surface of the concrete member. The materials and implementation approach were demonstrated in the laboratory on full-size specimens and were then applied to a RC bridge in the US that contained poorly detailed flexural steel and exhibited significant distress. 
Two independent experimental programs were conducted. In the first series, RC girders were strengthened in flexure and tested to failure in the laboratory, and the technique was then applied to an in-service bridge. For the second series, RC girders were strengthened in shear and tested to failure in the laboratory.

\section{Flexural Strengthening}

\subsection{Experimental Program}

An experimental program was developed to evaluate the effectiveness of the flexural strengthening approach using TiABs. Full-scale specimens were constructed to simulate as-built conditions of a RC bridge girder with poor flexural details from the mid-century period. Specimens were constructed, strengthened, and tested to failure. The specimens include a haunched and tapered section geometry. All specimens were $5.49 \mathrm{~m}$ long and had a $165 \mathrm{x} 914 \mathrm{~mm}$ deck. The stem dimensions were $229 \times 749 \mathrm{~mm}$ in the left half of the specimen and then transitioned to a cross section of $321 \times 1048$ $\mathrm{mm}$ through horizontal and vertical tapering after midspan as seen in Fig. 1a and 1b. The strength of the specimen was controlled by the poor splice detail located at the haunch transition. Smaller diameter bars of modern Grade 420 steel [1] were used to produce the flexural tensile force closest to that of the original design. All three specimens contained similar longitudinal reinforcing steel layout and materials. The steel details are also shown in Figs. 1a and $1 \mathrm{~b}$. The steel properties are shown in Table 1. The concrete was of lower strength concrete to mimic that used in the original design. The concrete properties were determined from $100 \times 400 \mathrm{~mm}$ diameter cylinders and the concrete compressive strength on the day-oftest are shown in Table 1.

The clear span and shear spans was selected to produce relative shear/moment demands similar to that of the controlling load case at the lap splice. Three specimens were constructed: Specimen FBase which represented the as-built condition without strengthening; Specimen FTiF which applied the NSM TiABs after first failing the specimen; and Specimen FTiU which applied the NSM TiABs with the specimen in an undamaged state.

Table 1: Material properties for test specimens.

\begin{tabular}{|c|c|c|c|c|c|c|c|c|c|c|c|c|c|c|c|}
\hline \multirow{3}{*}{$\begin{array}{c}\text { Specimen } \\
\text { FBase }\end{array}$} & \multirow{3}{*}{$\begin{array}{c}\begin{array}{c}\text { Concrete } \\
\text { Comp. } \\
(\mathrm{MPa})\end{array} \\
21.0 \\
\end{array}$} & \multicolumn{2}{|c|}{ M36 (\#11) } & \multicolumn{2}{|c|}{ M29 (\#9) } & \multicolumn{2}{|c|}{ M25 (\#8) } & \multicolumn{2}{|c|}{ M22 (\#7) } & \multicolumn{2}{|c|}{ M19 (\#6) } & \multicolumn{2}{|c|}{ M13 (\#4) } & \multicolumn{2}{|c|}{ Titanium } \\
\hline & & & & $\begin{array}{l}\mathrm{f}_{\mathrm{y}} \\
(\mathrm{M}\end{array}$ & $\begin{array}{l}\mathrm{f}_{\mathrm{u}} \\
\mathrm{oa})\end{array}$ & & & & & & & & & $\begin{array}{l}\mathrm{f}_{\mathrm{y}} \\
(\mathrm{M}\end{array}$ & $\begin{array}{l}f_{u} \\
a)\end{array}$ \\
\hline & & - & - & 432 & 703 & 438 & 773 & 450 & 721 & 434 & 733 & 346 & 549 & - & - \\
\hline FTiF & 25.0 & - & - & 432 & 703 & 438 & 773 & 450 & 721 & 434 & 733 & 346 & 549 & 1001 & 1090 \\
\hline FTiU & 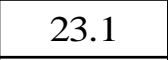 & - & - & 432 & 703 & 438 & 773 & 450 & 721 & 434 & 733 & 346 & 549 & 1001 & 1090 \\
\hline VBase & 3.6 & 478 & 740 & - & - & - & - & - & - & - & 682 & 350 & 544 & - & - \\
\hline VTi & 34.1 & 487 & 761 & - & - & - & - & - & - & 486 & 752 & 359 & 570 & 972 & 1042 \\
\hline
\end{tabular}

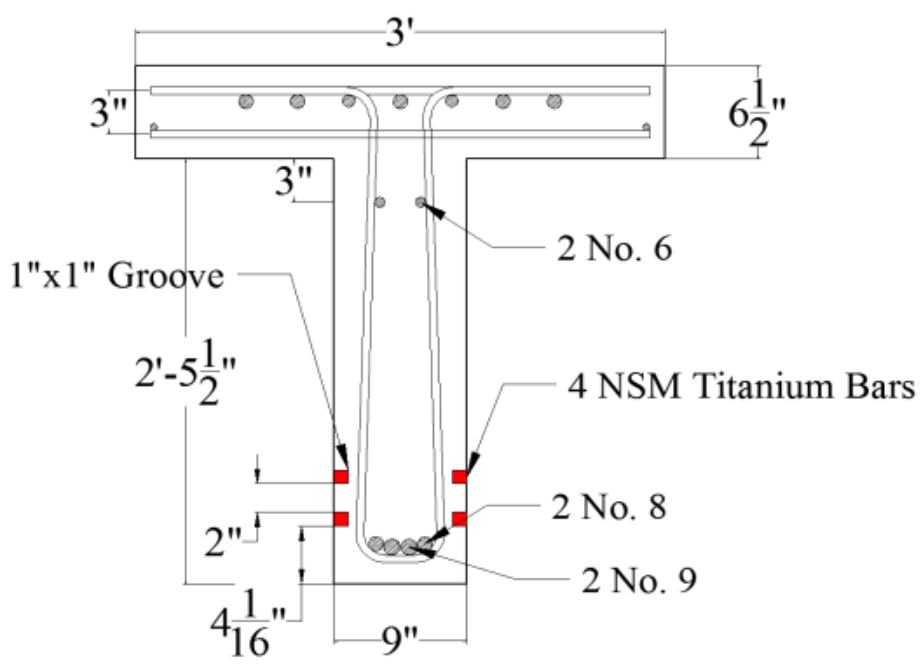


Fig. 1a: View of cross section of specimen (shown with NSM TiABs) $(1 \mathrm{in.}=25.4 \mathrm{~mm})$.

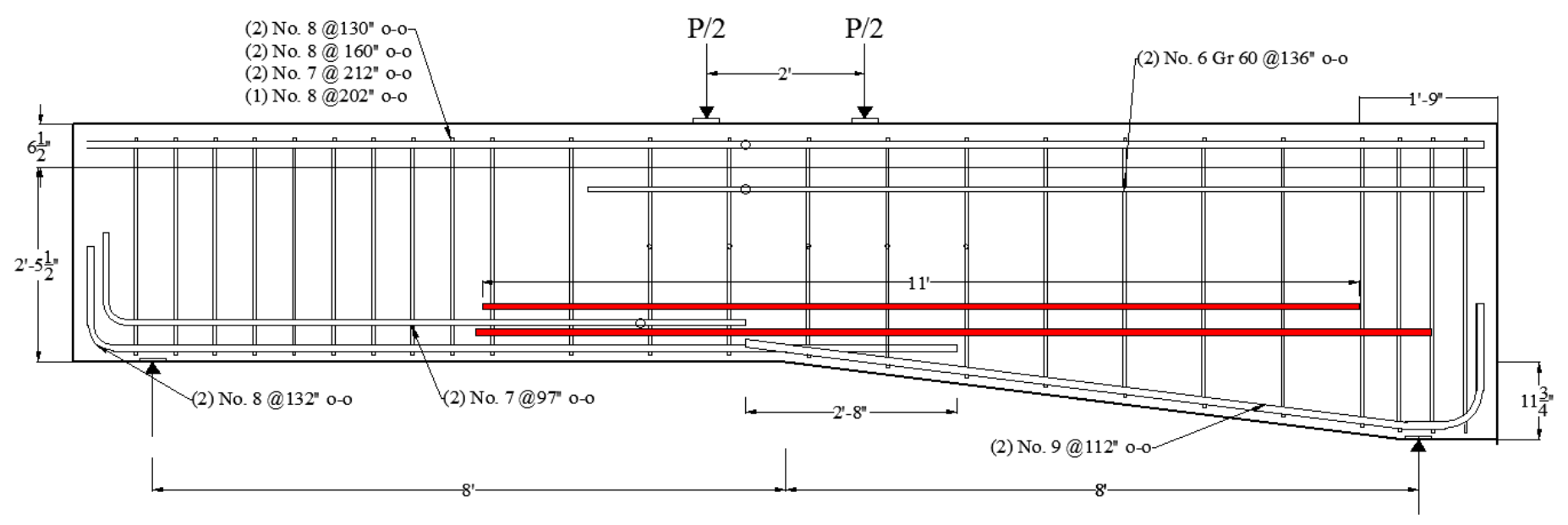

Fig. 1b: Elevation view of specimen FTiU (1 in.=25.4 mm).

The strengthening design approach was to fully restore the flexural capacity to the girders assuming the steel bars in the splice were continuous. This was accomplished using NSM TiABs. The titanium used for strengthening the specimens deserves special attention, as this is not a material commonly used in civil engineering practice. Titanium is nonmagnetic, has a low coefficient of thermal expansion of around $8.6 \mu \mathrm{m} / \mathrm{m}{ }^{\circ} \mathrm{C}$ ) at operating temperatures, and is impervious to commonly encountered sources of environmental deterioration which result in excellent long-term durability. The material unit weight is $4419 \mathrm{~kg} / \mathrm{m}^{3}$, about half that of steel. The nominal modulus of elasticity is $106,800 \mathrm{MPa}$, also about half that of steel. In this study, $16 \mathrm{~mm}$ diameter, round, TiABs were used in a NSM installation by placing them into concrete grooves cut into the concrete cover. NSM groove depth and spacing requirements were determined by [2]. The groove depth and width was $24 \mathrm{~mm}$ using a $16 \mathrm{~mm}$ diameter bar. The clear distance between grooves was approximately $76 \mathrm{~mm}$. The elevation of the NSM titanium was determined by the optimizing the effectiveness of the titanium (providing a large lever arm) and being spaced over the 22M (\#7) reinforcing steel bar.

The titanium alloy bars contain $6 \%$ aluminium and $4 \%$ vanadium, (so called Ti-6Al-4V) that meets [3], although these specifications do not adequately describe the material selected in this project. The annealed titanium alloy used in this study is produced to very tight tolerances on dimensions and material properties and is considered aircraft fastener grade. A unique surface treatment was developed to enhance bond between the TiAB and epoxy. The as-received titanium bars (with the surface treatment) were tested in uniaxial tension using a $50 \mathrm{~mm}$ gage length extensometer according to ASTM E8. A typical stress-strain plot from one of the samples is shown in Fig. 2. As seen here, the material does not exhibit a well-defined yield plateau and the yield stress is determined from the $0.2 \%$ strain offset. The average material properties from the Ti-6Al-4V tension samples were: yield stress of $1000 \mathrm{MPa}$ with $1.01 \%$ coefficient of variation (COV); ultimate stress of $10,090 \mathrm{MPa}$ with $0.88 \% \mathrm{COV}$; elongation of $11.3 \%$ with $2.66 \% \mathrm{COV}$; yield/tensile of 0.92 with COV of $0.17 \%$; and modulus of elasticity of $105,000 \mathrm{MPa}$ with COV of $0.55 \%$. The cross sectional area of the bars was determined by weighing long bars $(\sim 14.3 \mathrm{~m})$ of known length and dividing by the unit weight. The average area was $192 \mathrm{~mm}^{2}$ with COV of $0.18 \%$. As seen in these statistics, the variability of the titanium alloy bars was very low compared to conventional civil engineering materials.

To bond the titanium alloy bars into concrete grooves, structural epoxy was used. The epoxy was a commercially available general purpose gel epoxy adhesive widely used for bonding to concrete. The manufacturer reported epoxy material properties include tensile strength of $27.6 \mathrm{MPa}$, elongation at break of $1.0 \%$, compressive yield strength of 86.2 $\mathrm{MPa}$, and 2-day cure bond strength > $13.8 \mathrm{MPa}$. 


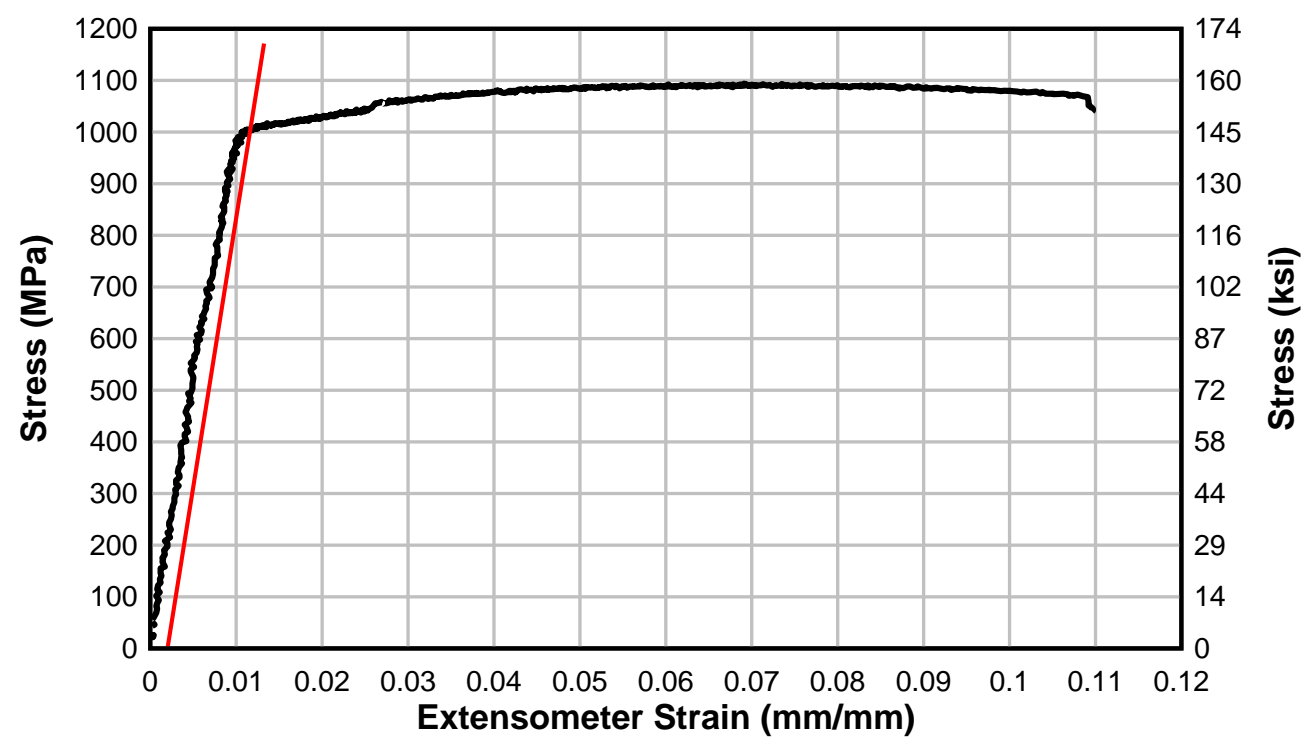

Fig. 2: Example uniaxial tension stress-strain response of titanium alloy bar with special surface treatment.

The design strength of the TiABs was taken as a yield stress of $1000 \mathrm{MPa}$. Four (4) NSM TiABs were required to provide the required member strength. The termination location for the NSM TiABs on the left side was determined by a diaphragm present at that end of the girder. The NSM TiABs on the right side of the specimen were terminated past the theoretical point of inflection for the continuous span represented by the specimen and the ends were staggered to minimize stress concentrations at the termination. TiABs were hooked to anchor them into $19 \mathrm{~mm}$ diameter drilled holes at the ends of cut concrete grooves. The hook tail length was $152 \mathrm{~mm}$ and the bend diameter was $51 \mathrm{~mm}$. The TiABs were warm worked to a maximum of $1250{ }^{\circ} \mathrm{F}$ with an acetylene torch prior to bending. Dead load was applied and held on the specimens during installation and curing (7 days) of the NSM TiABs, after which the specimens were tested.

Specimen FTiF was failed prior to installing the NSM TiABs. The loose and debonded concrete was removed from the anchorage region of the intersecting reinforcing steel bars at midspan. Then the cracks around the anchorage were epoxy injected. Once the epoxy injection was cured, the specimen was repaired with TiABs and then retested to failure in the retrofitted state.

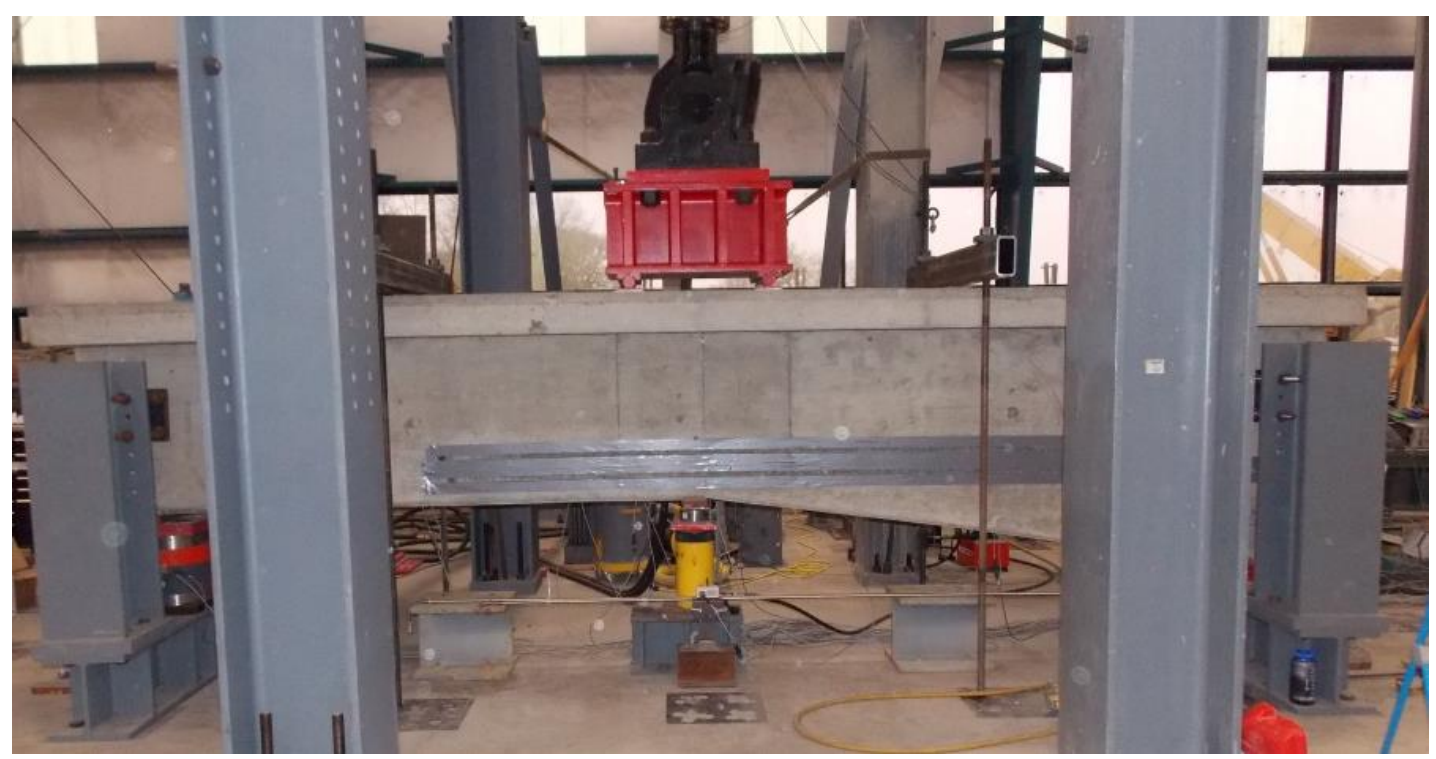

Fig. 3: View of flexural specimen in test setup. 


\subsection{Experimental and Analytical Results}

Three flexural specimens were tested to failure in the structural engineering laboratory at Oregon State University. The overall load-deformation response of specimens are shown in Fig. 4 along with the analytically predicted strengths and target demands. As seen here, the specimen representing the as-built conditions (FBase) exhibited low strength and no ductility. The failure occurred in the poorly detailed splice region at the haunch transition. The specimen strength was only marginally above the computed factored demands. The NSM TiAB specimens (FTiF and FTiU) achieved capacities more than double that of FBase and almost 4 times the deformation. The NSM strengthened specimens experienced ductile flexural failures and displayed distributed cracking and widespread signs of distress prior to failure.

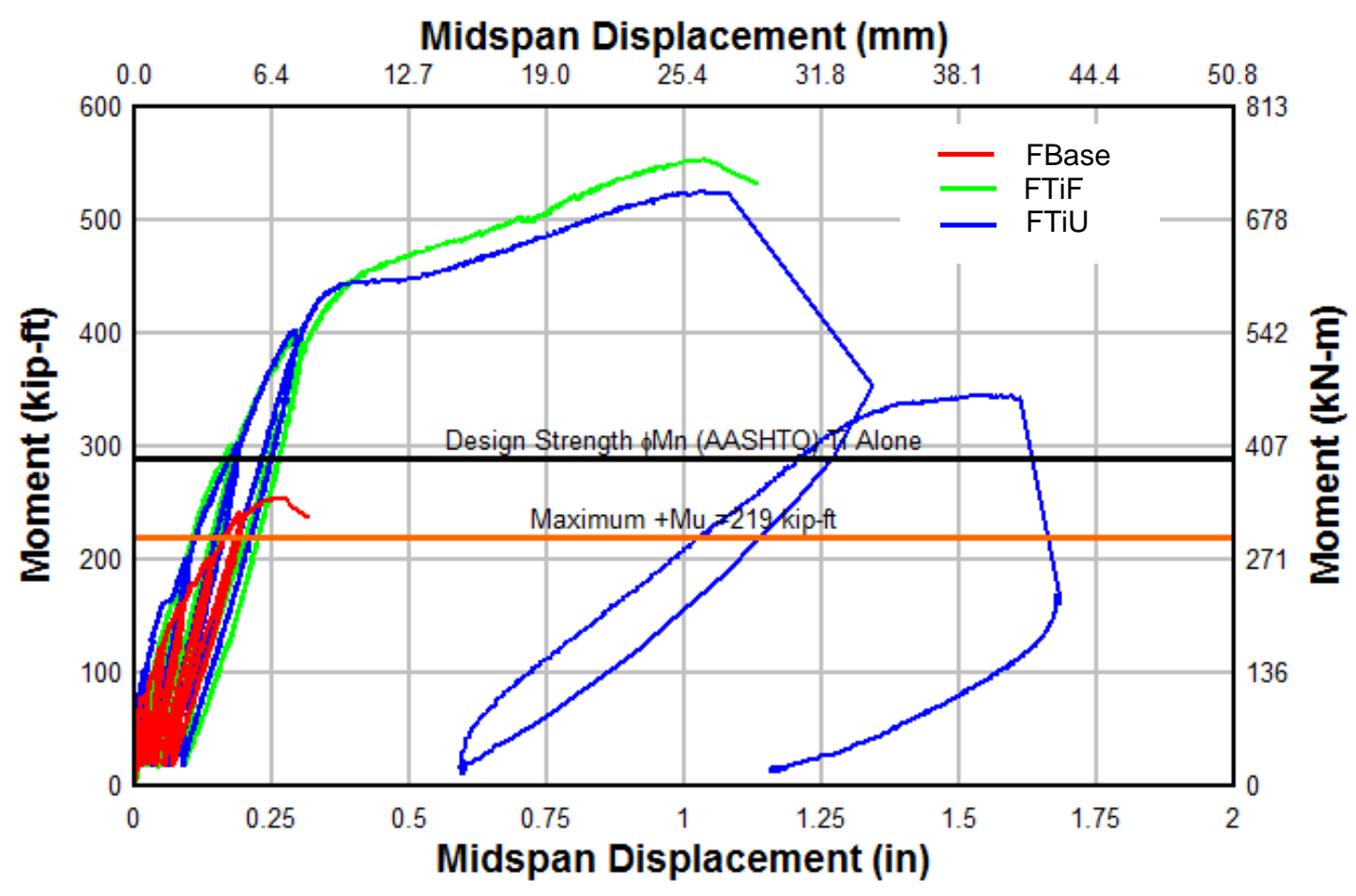

Fig. 4: Experimental flexural specimen responses with and without TiABs along with predicted capacity and design demands.

Specimen FTiF had a slightly lower initial stiffness than FTiU because initial cracking of the concrete and slip of the cutoff reinforcing steel bars occurred prior to installation of the NSM TiABs. Specimen FTiU contained NSM TiABs bonded to integral concrete that enabled stiffer response until an applied load of approximately $484 \mathrm{kN}$, when significant slip of the internal reinforcing steel occurred within the splice region that damaged the concrete to which the NSM TiABs were bonded. The damaged concrete around the bonded lengths of the NSM titanium bars contributed to the slight decrease in ultimate capacity compared to FTiF. Reserve capacity was observed for FTiU after achieving the peak load. This reserve capacity is seen as the last load cycle upon which FTiU achieved a load of $391 \mathrm{kN}$, even after fully failing the bond along the length of the NSM titanium alloy bars. The reserve capacity indicates that the mechanical anchorages on the titanium alloy bars could sustain loads above the factored demands even after bond rupture along the length that occurred at peak load.

The most conservative prediction of the NSM strengthened member flexural capacity using modified compression field theory [4] (relying only on the yield strength of NSM TiABs and assuming the internal steel provides no resistance) exceeded the factored moment demands as seen in Fig. 4. After completion of the experimental tests and analysis, the strengthening approach was applied to an in-service bridge on the US interstate system in Oregon, called the Mosier Bridge. The final cost of the NSM titanium alloy strengthening scheme was $30 \%$ less expensive than the NSM carbon fiber alternative. The Mosier Bridge is now the first reinforced concrete bridge in the world with TiAB strengthening. 


\section{Shear Strengthening}

\subsection{Experimental Program}

TiABs were also developed for shear strengthening applications. Only two specimens are presented here due to space limitations. The specimens were T-shaped full-size girders typical of mid-century US bridge design practice. The first specimen, VBase was unstrengthened and the second specimen, VTi, was the same but strengthened with TiABs. The cross sections and elevation views are shown in Fig. 5. As seen here, specimen VBase was strengthened using offset single leg stirrups. The TiABs used in this study were $6.3 \mathrm{~mm}$ diameter having cross-sectional area of $30.3 \mathrm{~mm} 2$. All TiAB bends were made about a $51 \mathrm{~mm}$ diameter pin with hook extensions of $57 \mathrm{~mm}$. The bars were mounted in grooves $9.5 \mathrm{~mm}$ wide and $13 \mathrm{~mm}$ deep. The TiABs were spaced at $305 \mathrm{~mm}$ and the epoxy was the same as that used in the flexural study. The concrete, reinforcing steel, and TiAB properties are shown in Table 1. The VBase specimen was tested at a span of $7.32 \mathrm{~m}$. Specimen VTi was initially tested at the same span, but since flexural failure was imminent, the supports were moved in to $6.64 \mathrm{~m}$, and a shear failure was obtained, thus the stiffer reloading branch as will be seen in the subsequent section.
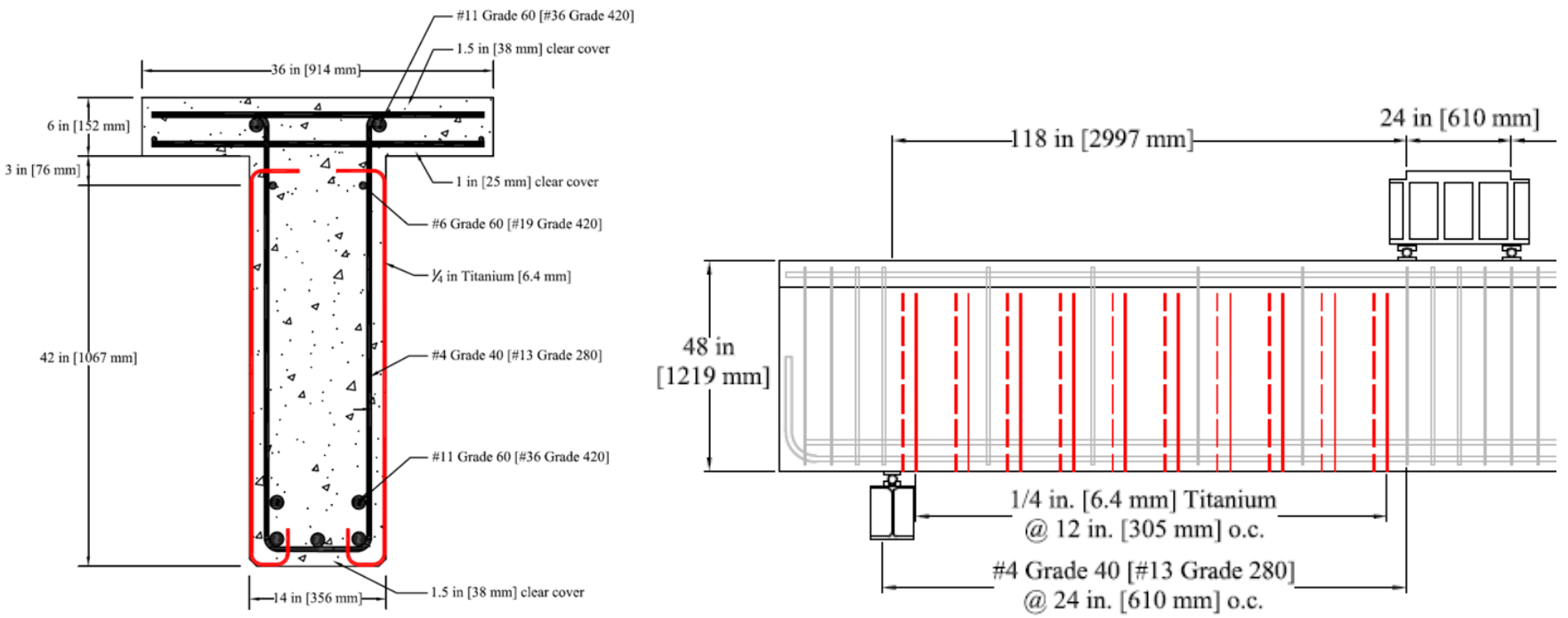

Fig. 5: Elevation views of shear specimens (red indicates location of TiABs).

\subsection{Experimental and Analytical Results}

The two specimens were tested to failure and the overall load-deformation response of specimens are shown in Fig. 6 . As seen in this figure, during the initial loading cycle, the TiAB strengthened girder exhibited a $40 \%$ increase in strength above the unstrengthened specimen (VBase) and would have produced a flexural failure at midspan if the supports had not been moved to reduce the moment demand and subsequently produced a shear failure at an even higher applied shear on the second loading cycle. Failure was initiated by shear-compression, which coincided with rupture of three titanium bars crossing the main diagonal crack. This demonstrated that the hooked details and available bond strength can effectively make use of the very high strength TiABs. The retrofit effectively would have transitioned the member from a nonductile shear failure (VBase) to a ductile flexural failure if the supports had not been moved. In addition, the NSM TiAB strengthened specimen exhibited widespread and distributed cracking as clear signs of distress prior to failure as seen in Fig. 7. Using available US design specifications, the shear strength of the specimens was conservatively and reasonably predicted using modified compression field theory [4] assuming full use of the yield strength of the TiABs. 


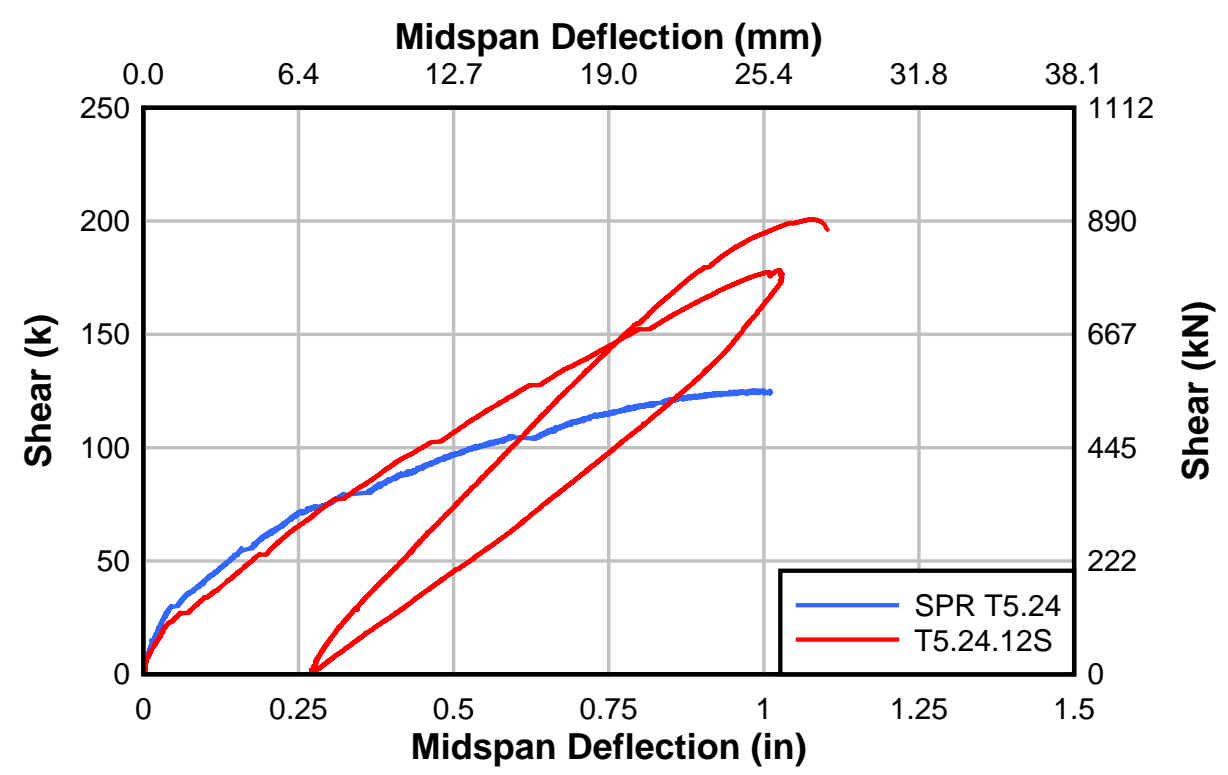

Fig. 6: Load-deflection response of shear specimens with and without NSM TiABs.

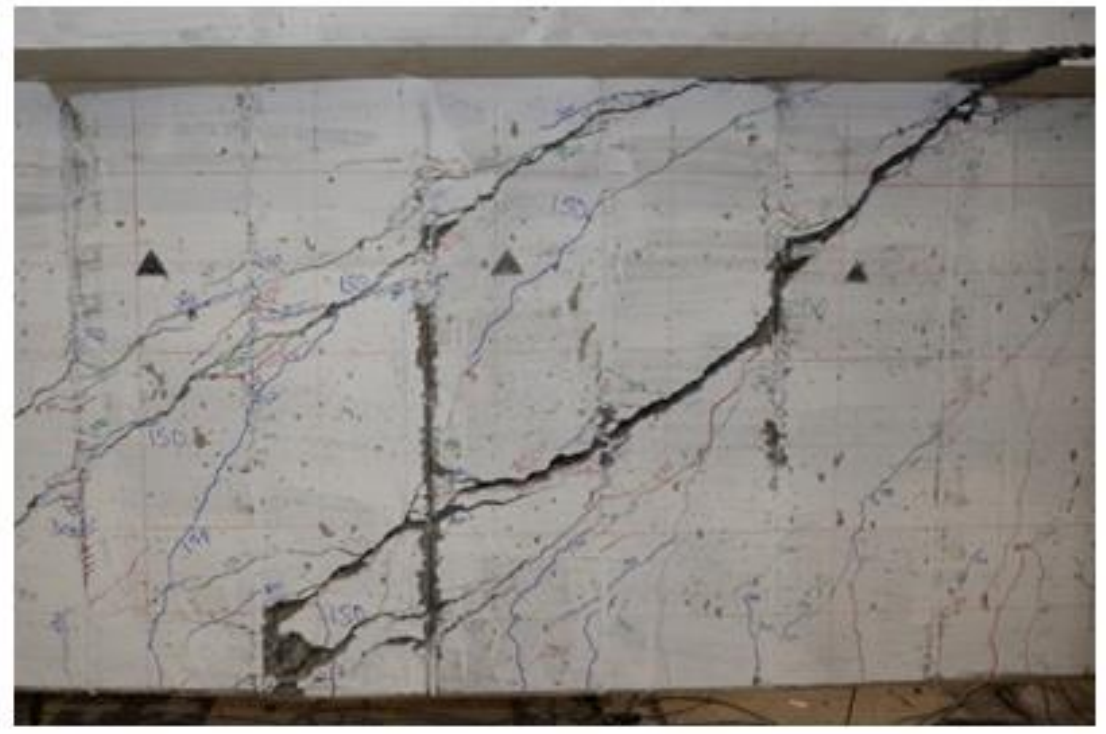

Fig. 7: Condition of VTi at failure.

\section{Conclusions}

Many older RC structures require strengthening to remain in service. In this study, RC girders simulating mid-century details were constructed, retrofitted, and tested to failure in the laboratory. These specimens were strengthened in flexure and shear using NSM titanium alloy bars. The flexural strengthening procedures were subsequently applied to an in-service bridge. Based on the results, the following conclusions are presented:

- Flexural strengthening with NSM TiABs increased the girder strength by a factor of two, and were well above the required factored load effects using only four TiABs. The NSM TiABs were able to provide strength well above the required factored load effects even if the underlying flexural steel had failed. to failure.

- The strengthening approach increased the girder deformation capacity and resulted in significant visual distress prior 
- The flexural strengthening technique was applied to an actual bridge and restored the bridge to full operation without shoring or posting at a cost $30 \%$ lower than alternatives.

- The NMS TiABs used for shear strengthening provided increased capacity $40 \%$ and would have shifted from nonductile shear failure to ductile flexural failure.

- For both flexure and shear, mechanical hooks at the ends of the TiABs allowed the member to continue to carry load after loss of epoxy bond along the length. No hook pullout prior to failure was observed.

- Design approaches using US design codes resulted in conservative design strengths for specimens strengthened in both shear and flexure when using the full yield strength of the TiABs.

- The high strength, ductility, environmental durability, and ability to fabricate mechanical anchorages make TiABs a promising material for strengthening civil infrastructure.

Additional information regarding the experiments and results for strengthening RC specimens with TiABs can be found [5], [6], [7], and [8].

\section{Acknowledgements}

This research was funded by the Oregon Department of Transportation and this support is gratefully acknowledged. Perryman Company, Houston, PA USA provided the BridgeAlloyTM titanium alloy bars with the surface deformations developed specifically for this application, the assistance of Mr. Warren George was greatly appreciated. The findings and conclusions are those of the authors and do not necessarily reflect those of the project sponsors, the individuals, or companies acknowledged.

\section{References}

[1] ASTM A706/A706M-09b, "Standard Specification for Low-Alloy Steel Deformed and Plain Bars for Concrete Reinforcement," ASTM International, West Conshohocken, PA, pp. 6, 2009.

[2] American Concrete Institute (ACI) 440.1R-12, "Guide for the Design and Construction of Structural Concrete Reinforced with Fiber-Reinforced Polymer Bars," Farmington Hills, MI., 2012.

[3] ASTM B348/B348M-13, "Standard Specification for Titanium and Titanium Alloy Bars and Billets," ASTM International, West Conshohocken, PA, 8 pp., 2013.

[4] American Association of State Highway and Transportation Officials (AASHTO), $7^{\text {th }}$ Edition, "AASHTO LRFD Bridge Design Specifications," Washington, D.C., 2014.

[5] C. Higgins, D. Amneus, L. Barker, "Methods for Strengthening Reinforced Concrete Bridge Girders Containing Poorly Detailed Flexural Steel Using Near-Surface Mounted Metallics," Final Report to Oregon Dept. of Transportation, Report No. FHWA-OR-RD-16-02, 2015.

[6] E. Vavra, "Application of Titanium Alloy Bars for Strengthening Reinforced Concrete Bridge Girders in Flexure," M.S. Thesis, School of Civil and Construction Engineering, Oregon State University, 2016.

[7] J. Knudtsen, "Shear strengthening reinforced concrete bridge girders using near-surface mounted titanium alloy bars," M.S. Thesis, School of Civil and Construction Engineering, Oregon State University, 2016.

[8] M. Lostra, "Seismic Performance of Square Reinforced Concrete Columns Retrofitted with Titanium Alloy Bars," M.S. Thesis, School of Civil and Construction Engineering, Oregon State University, 2016. 